\title{
ÍNDICE DE CAPACIDADE PARA O TRABALHO E IMAGEM CORPORAL EM FORMANDOS EM EDUCAÇÃO FÍSICA
}

\author{
André Luís Holzschuh ${ }^{1}$ \\ Luciane Sanchotene Etchepare Daronco ${ }^{2}$ \\ Laércio André Gassen Balsan ${ }^{3}$
}

HOLZSCHUH, A. L.; DARANCO, L. S. E.; BALSAN, L. A. G. Índice de capacidade para o trabalho e imagem corporal em formandos em educação física. Arq. Ciênc. Saúde Unipar, Umuarama, v. 18 n. 1, p. 9-17, jan./abr. 2014

\begin{abstract}
RESUMO: Avaliar os formandos de um curso de Educação Física torna-se importante, pois a partir dos resultados obtidos é possível perceber os motivos da ocorrência de dores, lesões e assim desenvolver ações que auxiliem os fatores intervenientes na saúde e na capacidade para o trabalho do futuro profissional. Em virtude disso, realizou-se uma pesquisa exploratória de caráter quantitativo. A amostra da pesquisa foi composta por 20 estudantes de Educação Física, voluntários, de ambos os sexos. Como instrumentos de coleta de dados foram utilizados cinco questionários que objetivaram avaliar a dor, as lesões, a imagem corporal e a capacidade para o trabalho. Os resultados demonstram que os indivíduos têm boa capacidade para o trabalho, contudo o número de lesões sofridas e a incidência de dores é muito alta. Já os resultados da Imagem Corporal apontam que em geral os alunos do curso de Educação Física estão satisfeitos com seu corpo.

PALAVRAS-CHAVE: Índice de capacidade para o trabalho; Imagem corporal; Dor; Lesão.
\end{abstract}

\section{WORK ABILITY INDEX AND BODY IMAGE IN PHYSICAL EDUCATION UNDERGRADUATES}

ABSTRACT: Evaluate the undergraduates in a Physical Education course is important, since from the results obtained, it is possible to understand the reasons for the occurrence of pain and injuries and thus develop actions that help the factors involved in health and work ability of the future professional. A quantitative exploratory study was performed, with the study sample consisting of 20 physical education undergraduates, volunteers of both sexes. Five questionnaires were used as data collection instruments; aimed to evaluate pain, injury, body image and ability to work. The results demonstrate that individuals have good workability; however, the number of injuries suffered and the incidence of pain is very high. The Body Image results show that, in general, the Physical Education undergraduates are happy with their body.

KEYWORDS: Work ability index; Body image; Pain; Injury.

\section{Introdução}

Atualmente a mídia vem impondo para a sociedade, padrões de beleza, peso ideal, silhuetas extremamente fora da realidade de muitas pessoas. E isso, vem atingindo as pessoas tornando-as insatisfeitas com a sua imagem corporal. Segundo Morgado et al. (2009) na sociedade pós-moderna, o ideal cultural de corpo é aquele atlético, musculoso, magro e belo. Vive-se numa busca incessante por um corpo dito perfeito, massificado e moldado conforme interesses de uma indústria cultural. Em consequência disso, muitas pessoas se envolvem mesmo que involuntariamente em distúrbios dismórfico-corporais.

A Educação Física é vista como uma área de conhecimento essencialmente prática, buscando assim atender necessidades físicas dos indivíduos, aquisição de habilidades motoras e desenvolvimento de capacidades físicas para fins atléticos. Com a difusão nos meios de comunicação sobre a atividade física orientada e os benefícios que ela pode proporcionar os espaços onde são oferecidas essas atividades são amplamente procurados por pessoas que almejam uma melhor qualidade de vida e também uma melhor imagem corporal.

Com esse aumento no mercado de trabalho, muitas pessoas buscam a qualificação e a atualização na área. A preocupação somente com o aprendizado acaba fazendo passar despercebido se esses profissionais estão aptos ao trabalho, não se limitando somente a instrução, mas também ao aspecto da saúde do trabalhador, pois esse necessitará de plenas condições físicas e mentais para desempenhar seu trabalho.

Nesse sentido, avaliar os formandos do curso de Educação Física torna-se importante tema de estudo, pois a partir dos resultados obtidos é possível perceber os motivos da ocorrência de dores, lesões e assim desenvolver ações que atuem nos fatores intervenientes da saúde e da capacidade para o trabalho do indivíduo.

Dessa forma, chegou-se a seguinte inquietação: "Qual o índice de capacidade para o trabalho, incidência da dor e a percepção da imagem corporal em formandos de Educação Física?" Com base nessa problemática, o presente estudo objetivou: (I) verificar o índice da capacidade para o trabalho de alunos formandos em Educação Física; (II) verificar a Imagem Corporal dos alunos formandos em Educação Física; (III) verificar a incidência de Dor dos formandos em Educação Física; e, (IV) verificar a incidência de Lesões dos formandos em Educação Física.

\section{Capacidade para o Trabalho e Índice de Capacidade para o Trabalho}

O conceito de Capacidade para o Trabalho baseia-se em quão bem está ou estará um trabalhador e quão capaz ele está para executar seu trabalho, em função das exigências de seu estado de saúde física e mental (TUOMI et al., 2005).

DOI: https://doi.org/10.25110/arqsaude.v18i1.2014.5152

${ }_{1}^{1}$ Universidade Federal de Santa Maria, Graduação em Educação Física; Endereço: Rua Frederico Varaschini, 730, Bairro Camobi, Santa Maria, CEP 97105160. Rio Grande do Sul / Brasil. E-mail: andreluisholzschuh@yahoo.com.br

${ }^{2}$ Universidade Federal de Santa Maria, Doutorado em Ciência do Movimento Humano; Endereço: Rua Quintino Bocaiúva, 366 / 902 - Bairro Centro. Santa Maria, CEP: 97010-400. Rio Grande do Sul / Brasil. E-mail: luetchepare@gmail.com

${ }^{3}$ Universidade Federal de Santa Maria, Graduação em Educação Física e Mestre em Administração; Endereço: Rua Onze de Julho, 75 - Bairro Camobi. Santa Maria, CEP 97105-302 Rio Grande do Sul / Brasil. E-mail: laerciobalsan@yahoo.com.br 
O autor ainda cita que a capacidade para o trabalho é a base do bem estar para o ser humano e não permanece satisfatória ao longo da vida, sendo afetada por muitos fatores. Entretanto, um ambiente de trabalho saudável e um estilo de vida ativo mudam este prognóstico.

A manutenção de uma adequada capacidade para o trabalho está associada às boas condições de trabalho e de vida, incluindo estilos de vida saudáveis (FISCHER et al., 2005) sendo que as exigências físicas e mentais do trabalho não devem ser elevadas (TUOMI et al., 2004). A capacidade para o trabalho, quando considerada como o desempenho efetivo e eficiente de tarefas dentro de uma atividade previamente determinada resulta em bem-estar para todos os trabalhadores, assim, é necessário intervir positiva e precocemente para manter uma boa qualidade de vida no trabalho e na vida pessoal dos trabalhadores (VAHL NETO, 1999).

Um equilíbrio entre a capacidade dos trabalhadores e as exigências e fatores estressantes do trabalho é necessário a fim de a capacidade para o trabalho não seja diminuída. Em vista disso, é necessária uma avaliação frequente dos agentes que desencadeiam sintomas, lesões, doenças e melhorias das condições de trabalho visando o equilíbrio entre capacidade e exigências de trabalho (BELLUSCI; FISCHER, 1999).

O Índice de Capacidade para o Trabalho - ICT foi desenvolvido no Finnish Institute of Occupational Health (Instituto Finlandês de Saúde Ocupacional) pelos pesquisadores: Tuomi, Ilmarinen, Jankola, Katajarinne e Tulkki; através de pesquisas acompanhando servidores municipais em processo de envelhecimento na década de 80 (TUOMI et al., 1998). Esse questionário foi traduzido do original em Inglês para o Português por um grupo multidisciplinar de pesquisadores e adaptado para a Língua Portuguesa falada no Brasil. Foi publicado em Português pelo Finnish Institute of Occupational Health em 1997 e posteriormente pela EDUFSCAR em 2005 (TUOMI et al., 2005).

O ICT é um instrumento que revela quão bem um trabalhador é capaz de realizar seu trabalho. É determinado pelas respostas das várias questões que o compõem, que levam em consideração as demandas físicas e mentais do trabalho, o estado de saúde e capacidades.

O questionário é preenchido pelo próprio trabalhador, desta forma o resultado revela a percepção que o trabalhador tem sobre a própria capacidade para o trabalho. É composto por sete itens, cada um compreendendo uma, duas ou três questões e a cada resposta é creditado um número de pontos (escore) (TUOMI et al., 2005).

A capacidade para o trabalho tem sido investigada em indivíduos adultos de diferentes profissões, tanto nas funções operacionais que requerem grande esforço físico (WALSH et al., 2004; ANDRADE e MONTEIRO, 2007), como em funções predominantemente cognitivas, como nos cargos administrativos (BELLUSCI; FISCHER, 1999; MARTINEZ; LATORRE, 2006).

Martinez e Latorre (2006), ao pesquisar a associação entre saúde e capacidade de trabalho com 224 empregados de uma empresa de auto-gestão de planos de previdência privada e de saúde na cidade de São Paulo verificaram que as dimensões da saúde física e mental estiveram positiva e significativamente associadas à capacidade para o trabalho, independente de características demográficas e ocupacionais, concluindo que quanto melhor o estado de saúde, melhor a condição da capacidade para o trabalho do indivíduo.

Em estudo realizado por Monteiro e Fernandes (2006), com trabalhadores de uma empresa de tecnologia de informação, observou uma associação significativa entre atividade física e ICT numérico, com maior escore para os que realizavam atividade física, assim, os pesquisadores concluíram que a atividade física foi um dos fatores explicativos da melhor capacidade para o trabalho, de forma que os trabalhadores sem atividade física tinham 2,5 vezes mais risco de ter ICT moderado ou bom do que aqueles que praticavam alguma atividade física.

\section{Lesões}

$\mathrm{O}$ esporte e qualquer atividade física imprimem em sua prática um risco de lesão, sendo o excesso de treinamento um fator causador de lesões. Nos esportes, a necessidade de vitórias e resultados inéditos, reflete um número crescente de lesões do aparelho locomotor nos atletas de alto nível, cujas causas supostamente podem ser atribuídas à ausência de medidas preventivas, exaustão competitiva, volúpia atlética e psicossomatismos (GANTUS; ASSUMPÇÃO, 2002).

As lesões (contusões, entorses, luxações, entre outros) ocorrem durante a prática de atividades físicas em geral, não apenas durante atividades esportivas de competição e durante a preparação para os eventos competitivos, sendo a inflamação a resposta inicial de todos os tecidos à lesão e também o início do processo reparador (KOLT; SNYDER-MACKLER, 2008).

De acordo com Rose Júnior (2006) existem dois tipos de lesões: crônica e aguda. A lesão crônica consiste do excesso de treinamento, cargas repetidas, técnica errada, ou decorrente de lesões mal curadas. Com esses agravantes é gerado sobrecarga na articulação e no grupo muscular envolvido. As lesões agudas podem ser resultado de um único trauma, ou de degeneração tecidual de uma lesão crônica.

Para Flegel (2002), os músculos que geralmente sofrem lesão são: quadríceps, manguito rotador, posterior de coxa e panturrilha. Já os tendões que são mais lesionados são o tendão de Aquiles, tendão patelar, tendão do bíceps e tendão do músculo do manguito rotador.

Segundo Oliveira (1991), os estágios mais severos das lesões músculo-esqueléticas são acompanhados de sinais e sintomas clínicos intensos, que envolvem parestesias e perda de força muscular. A persistência desses sintomas tende a inibir as atividades diárias domésticas e ocupacionais. Por sua vez, a inatividade por períodos prolongados pode gerar hipotrofia muscular e perda das amplitudes articulares funcionais. Caso esse ciclo não seja rompido, a capacidade funcional, que inclui a capacidade para o trabalho, estará comprometida.

O estudo de Murofuse e Marziale (2001), que ao investigar as principais mudanças no trabalho e na vida de um grupo de trabalhadores do setor bancário do município de Cascavel - PR acometidos com Lesões por Esforços Repetitivos (LER) confirma que os trabalhadores enfrentaram limitações físicas que impediram a execução de atividades rotineiras, de cuidados pessoais e domésticos, passando a depender de outras pessoas devido à incapacidade de alimentar-se, higienizar-se e vestir-se. Ocorreram também alterações nos hábitos de prática de exercícios físicos dos entrevistados, 
tais como: natação, caminhadas e futebol.

Entre trabalhadores fala-se comumente em Lesões por Esforços Repetitivos (LER) e/ou Distúrbios Osteo-musculares Relacionados ao Trabalho (DORT). As LER/DORT são afecções músculo-esqueléticas onde o ambiente e as condições de trabalho contribuem para o seu aparecimento e/ou piora. As condições de trabalho que podem levar ao seu aparecimento incluem movimentos repetitivos, aplicação de força, principalmente com as mãos, levantamento e transporte de pesos, posturas inadequadas e estresse, relacionado às condições psicossociais onde o trabalho acontece. O surgimento dessas afecções está ligado à exposição a esses riscos, sua magnitude, intensidade, frequência, duração da exposição e da capacidade individual de lidar com as exigências do trabalho (MACIEL, 2000).

As LERs/DORTs têm chamado a atenção não só pelo aumento de sua incidência, mas também por existirem evidências de sua associação com o ritmo de trabalho. Apresentam sinais e sintomas de inflamações dos músculos, tendões, fáscias e nervos dos membros superiores, cintura escapular e pescoço, entre outros. Essas patologias, em geral, não têm um tratamento difícil, mas possuem uma má evolução, causam dor, perda de força, edema e são responsáveis por um número significativo de queda de desempenho no trabalho (REGIS FILHO; MICHELS; SELL, 2006).

Para Salim (2003), as LER/DORT não são doenças recentes, mas estão assumindo um caráter epidêmico, sendo algumas de suas patologias crônicas e de difícil terapia, porque retornam quando é retomada a execução dos movimentos repetitivos, gerando uma incapacidade para a vida e não apenas para o trabalho.

Os DORT podem gerar diferentes graus de incapacidade funcional, e são considerados um dos mais graves problemas da saúde do trabalhador. A incidência dos DORT é maior entre os trabalhadores jovens e as mulheres são as mais atingidas, prevalecendo a faixa etária de 20 a 39 anos (COUTO, 1988).

Os pesquisadores Monteiro, Alexandre e Rodrigues (2006), ao investigar as doenças musculoesqueléticas referidas com diagnóstico médico entre trabalhadores de uma instituição de saúde, observaram que as doenças musculoesqueléticas predominam entre os indivíduos que desenvolvem trabalhos com demandas predominantemente físicas, que incluíam ocupações como auxiliares de serviço e oficiais de serviço de manutenção. Entre os obesos, 68\% apresentaram doenças músculo esqueléticas.

\section{Dor}

A dor é um sintoma subjetivo, sendo definida como uma sensação desagradável, resposta emocional e estímulo associado à lesão tecidual real ou potencial; é influenciada por fatores psicológicos. É uma experiência que mistura características físicas, motivacionais, afetivas e cognitivas do indivíduo, influenciada por experiências passadas e presentes (SANTOS, 1996).

Segundo Caudill (1998) a dor, é um componente vital de experiência humana que possui diversos significados: Biologicamente: é um sinal de que o corpo foi danificado; Psicologicamente: é experienciada como um sofrimento emocional; Comportamento: altera a maneira de uma pessoa se movimentar e agir; Cognitivamente: exige que se pense no seu significado, sua causa e possíveis tratamentos; Espiritualmente: tem sido um lembrete da mortalidade; Culturalmente: é usada para testar a coragem das pessoas ou para forçar sua submissão.

A sensação de dor é influenciada por um componente sensorial e por um componente perceptivo, em que se observa a influência da cognição, do estilo de personalidade, da cultura, da experiência anterior com a dor e do significado da dor para cada indivíduo (DUARTE; GOULART; PENNA, 1999).

De acordo com Caudill (1998) a dor pode ser classificada como aguda e crônica: a dor aguda é aquela que geralmente tem uma fonte identificável e duração limitada. Como exemplos são citados: a resposta ao tocar em um ferro quente, onde dentro de um período de tempo a queimadura sara; apendicite, onde o apêndice é retirado e a ferida cirúrgica cicatriza; e dores de parto, que cessam com o nascimento da criança. Em geral, as pessoas recuperam-se da dor aguda num período de tempo razoavelmente limitado. No início da dor, pode ocorrer o sentimento de ansiedade ou medo, que devem diminuir quando o problema é identificado, o tratamento é iniciado e a recuperação começa a ocorrer. Já a dor crônica ocorre quando o próprio mecanismo para a dor não funciona adequadamente ou quando determinadas doenças associadas à dor tornam-se crônicas por razões desconhecidas. Isso resulta em dor contínua e o próprio sintoma torna-se uma doença. Com frequência, a dor crônica é mal definida no que se refere à sua fonte ou causa, durando mais do que três meses e, comumente, está associada a múltiplas consequências biológicas, psicológicas e sociológicas. Como exemplos são citados: dor nas costas ou no pescoço, cistite intersticial, neuropatia diabética, dores de cabeça e fibromialgia.

Uma variação da dor crônica é a dor crônica intermitente que ocorre com períodos sem dor, alternados com semanas ou até meses de dor diária. São exemplos de dor crônica intermitente as enxaquecas, a artrite reumatóide e a síndrome do cólon irritável (CAUDILL, 1998).

Santos (1996) relata que em estudos da população geral, a cabeça e os membros inferiores são apontados como os locais mais comuns de dor aguda, e a coluna como o local mais comum de dor crônica.A dor quando não tratada adequadamente afeta a qualidade de vida das pessoas em todas as dimensões: físicas, psicológicas, sociais e espirituais (RIGOTTI; FERREIRA, 2005).

O conceito de que postura defeituosa é capaz de causar condições dolorosas é geralmente aceito no campo da saúde. Nos casos em que a postura defeituosa não apresenta dor, o fato é explicado quando o indivíduo é flexível à mudança de posição do corpo (KENDALL; McCREARY, 1987).

Segundo os mesmos autores, os casos de dor postural variam muito na forma de início, na gravidade dos sintomas e na natureza da mecânica defeituosa associada. Em alguns casos aparecem sintomas agudos, geralmente como resultado de um esforço inusitado ou uma lesão, nos quais não há mecânica corporal defeituosa predisposta. Outros casos têm início agudo e desenvolvem sintomas dolorosos crônicos.

A dor lombar e/ou cervical, geralmente é resultado de fraqueza muscular da região envolvida, e de uma mecâ- 
nica e postura inadequadas, quando não tratada, pode facilmente transformar-se em dor crônica. Entretanto, há possibilidade que essa dor seja sintoma de um problema mais grave (MOFFAT; VICKERY, 2002).

Walsh et al. (2004) ao relacionar a intensidade de dor, com o ICT em trabalhadores da linha de produção de uma empresa multinacional de médio porte, situada no interior do estado de São Paulo, produtora de materiais escolares e para escritório observaram que $97 \%$ dos trabalhadores que assinalaram sentir dor entre zero e dois, ou seja, nenhuma ou mínima dor, possuem ICT bom (30\%) e excelente (67\%). Por outro lado, $74 \%$ dos que assinalaram dor entre sete e 10 possuem ICT pobre (39\%) e moderado (35\%).

Na tentativa de documentar de forma objetiva a dor, foram desenvolvidos vários protocolos de avaliação, seguem alguns dos mais utilizados em pesquisas e na prática clínica (MIGUEL, 2007):

- Escala de quantificação verbal: a dor é identificada com uma única palavra (nenhuma dor, dor branda, moderada, grave ou insuportável).

- Escala de quantificação numérica: a dor é quantificada em uma escala de 0 a 10 ou de 0 a 100 . O zero indica a ausência de dor e os pontos 10 e 100 representam a pior dor possível.

- Escala análoga visual de dor: consiste em uma linha de 10 centímetros com âncoras verbais típicas de "ausência de dor" à esquerda e "a pior dor possível" à direita, quando a escala é orientada no plano horizontal. A pessoa colocará um marco vertical em um ponto da linha que corresponde à gravidade de sua dor.

- Escala análoga de cores: as várias posições da escala são marcadas por tons de vermelho progressivamente mais escuros. $\mathrm{O}$ escore do sujeito é o valor numérico no verso da escala que coincide com a posição escolhida.

- Escala de dor de faces: mensura primariamente a intensidade da dor e em menor extensão seus componentes afetivos. Consiste no desenho de sete faces alinhadas.

- Questionário de dor de McGill: onde são registrados, a localização da dor, a sua intensidade e o seu comportamento por meio de três partes.

- OLD CART: avalia o início, a localização, a duração, as características, os fatores agravantes e atenuantes da dor, bem como os tratamentos aplicados.

- Minimum Data Set: reflete a dor vivenciada na semana anterior ao teste. $\mathrm{Na}$ escala há dois itens que medem a frequência e a intensidade da dor e três pontos com descritores verbais.

- Proxy PainQuestionary (PPQ): avaliação da presença, frequência e intensidade da dor. O primeiro item possui perguntas com o formato "sim" ou "não" e os outros dois itens são graduados em uma escala horizontal de 13 pontos, ligada a descrição verbal. É administrado por meio de entrevista.

- Escala Funcional da dor: possui três níveis de avaliação, numérico (0 a 5), descritivo (sem dor à dor intolerável) e funcional (sem limitações à incapaz de se comunicar verbalmente devido a dor).

\section{Imagem corporal}

A forma que o corpo se apresenta para cada sujei- to pode ser considerada com a imagem corporal e sua determinação é formada, tanto em relação às outras pessoas, como em relação a si próprio (CASH; PRUZINSKY, 1990). Inúmeros fatores de origem psicológica, ambiental, física, comportamental e cultural podem influenciá-la, dentro da subjetividade de cada sujeito, tais como sexo, idade, meios de comunicação, raça, crenças e valores (RICCIARDELLI; McGAB; BANFIELD, 2000).

Shilder (1999) aponta várias colocações importantes em seu conceito. Segundo ele, a imagem do corpo humano e a figuração de nosso corpo é formada em nossa mente. $\mathrm{O}$ esquema do corpo é a imagem tridimensional que todos têm de si mesmos, podendo chamá-la de imagem corporal.

A imagem corporal é uma construção multidimensional que descreve amplamente as representações internas da estrutura corporal e da aparência física, em relação a nós mesmos e aos outros (CASH; PRUZINSKY, 1990). O processo de formação da imagem corporal pode ser influenciado pelo sexo, idade, meios de comunicação, bem como pela relação do corpo com os processos cognitivos como crença, valores e atitudes inseridos em uma cultura (RICCIARDELLI; McGAB; BANFIELD, 2000; DAMASCENO et al., 2006).

Segundo Thompson (1996), a utilização do termo imagem corporal seria uma maneira de padronizar os diferentes componentes que integram a imagem corporal. Dentre eles, tem-se: satisfação com o peso, acurácia da percepção do tamanho, satisfação corporal, avaliação da aparência, orientação da aparência, estima corporal, corpo ideal, padrão de corpo, esquema corporal, percepção corporal, distorção corporal e desordem da imagem corporal, dentre outras.

Considerando que as relações entre as desordens alimentares e percepção da imagem corporal são bem documentadas na literatura (MADRIGAL et al., 2000; PESA; SYRE; JONES, 2000), Leonhard; Barry (1998), relatam o fato de os estudos sobre distorção e insatisfação com a imagem corporal focalizam essencialmente populações portadoras de transtornos alimentares específicos (bulimia, anorexia nervosa e obesidade mórbida). É recente a observação desse tipo de distorção em sujeitos eutróficos isentos de transtornos alimentares específicos.

Atualmente as relações com o corpo são amplamente influenciadas por diversos fatores socioculturais. Esses fatores conduzem homens e mulheres a apresentarem um conjunto de preocupações e insatisfações com a imagem corporal, induzindo-os a se exercitarem, a cuidarem de seus corpos, direcionando-os a desejos, hábitos e cuidados com a aparência visual do corpo (BLOWERS et al., 2003; POPE; PHILIPS; OLIVARDIA, 2003).

Segundo Thompson (1996), o conceito de imagem corporal envolve três componentes:

- Perceptivo, que se relaciona com a precisão da percepção da própria aparência física, envolvendo uma estimativa do tamanho corporal e do peso;

- Subjetivo, que envolve aspectos como satisfação com a aparência, o nível de preocupação e ansiedade a ela associada;

- Comportamental, que focaliza as situações evitadas pelo indivíduo por experimentar desconforto associado à aparência corporal.

Para avaliar a percepção do indivíduo em relação a sua imagem corporal utiliza-se a escala de nove silhuetas na 
qual o individuo sinaliza a imagem semelhante à aparência corporal real (Percepção da Imagem Corporal Real - PICR) e também o número da silhueta que acredita ser mais condizente à aparência corporal ideal (Percepção da Imagem Corporal Ideal - PICI).

A insatisfação com a imagem corporal é apontada como um fator de risco para depressão e baixa auto-estima nas diferentes faixas da adolescência (PAXTON; EISENBERG; NEUMARCK-SZTAINER, 2006; SULJOLDZIC; DE LUCIA, 2007). Além disso estudos tem identificado prevalências de insatisfação com imagem corporal em crianças e adolescentes em torno de $20 \%$ a $60 \%$ dependendo de fatores como o sexo, etnia, estado nutricional e socioeconômico e também às diferentes formas de avaliação (CONTI; FRUTUOSO; GAMBARDELLA, 2005; ROBINSON et al., 2001; O’DEA, 2008).

\section{Material e Método}

Para se atingir os objetivos propostos realizou-se uma pesquisa exploratória de caráter quantitativo. A amostra foi composta por 20 estudantes de Educação Física, voluntários do Centro de Educação Física e Desportos (CEFD), da Universidade Federal de Santa Maria - RS, de ambos os sexos.

Como instrumentos de coleta de dados foram utilizados cinco questionários:

- Questionário de Mc Gill adaptado (DORE; GUERRA, 2006) - para avaliação da dor.

- Questionário IMR Adaptado de Pastre et al. (2004) - para avaliação de lesões.

- Questionário Índice de Capacidade para o Trabalho de TUOMI et al., (1997) - para verificar o índice de capacidade para o trabalho e as lesões sofridas pelos alunos.

- Questionário BodyShapeQuestionnaire - BSQ (COOPER et al., 1987) - para avaliação da preocupação com a Imagem Corporal.

- Teste das Figuras de Stunkard (1983) - para avaliação da imagem corporal.

Para a realização da pesquisa, encaminhou-se uma carta de apresentação ao Centro de Educação Física e Des- portos da Universidade Federal de Santa Maria - RS explicando a pesquisa e solicitando autorização para sua realização. Após a autorização realizou-se uma reunião com os alunos do Curso de Educação Física para explicar sobre os objetivos do estudo, a confidencialidade dos dados, o tratamento estatístico e a disponibilidade dos resultados. Além disso, nesse momento foi entregue o Termo de Consentimento Livre e Esclarecido (TCLE) que foi assinado pelos alunos que concordaram em participar da pesquisa.

A coleta de dados foi realizada por acadêmicos e profissionais da área da Educação Física, integrantes do Núcleo de Estudos em Medidas e Avaliação para Educação Física e Saúde (NEMAEFS), que já possuíam experiência nas avaliações. Os acadêmicos do NEMAEFS participaram de encontros teóricos para conhecimento do estudo e de um treinamento prático para esclarecer possíveis dúvidas.

A coleta de dados aconteceu no Centro de Educação Física e Desportos/ UFSM. Os alunos responderam aos questionários separados por turmas.

Os dados obtidos por meio dos questionários foram quantitativamente analisados, por meio do software SPSS versão8.0. Inicialmente, realizaram-se análises descritivas (de tendência central e de dispersão) e posteriormente foi feita uma análise interpretativa relacional dos dados.

\section{Resultados e Discussão}

No que diz respeito à classificação do ICT e de acordo com os valores internacionalmente padronizados, 14 indivíduos da amostra apresentaram um ICT de boa capacidade para o trabalho e 6 indivíduos com ótima capacidade para o trabalho.

O número de lesões relatadas pelos alunos dos cursos de Educação Física é expressivo, dos 20 indivíduos somente 7 não relataram qualquer lesão, já os 13 indivíduos restantes somaram 32 lesões, sendo que as mais frequentes são: entorse com 13 ocorrências, seguido por distensão muscular com 7 ocorrências. A Tabela 1 demonstra a frequência das lesões, a parte do corpo em que ocorreu a lesão e a atividade que o aluno estava praticando no momento da lesão.

Tabela 1: Análise das lesões

\begin{tabular}{|c|c|c|c|c|}
\hline Tipo de lesão & Frequência & Local Anatômico & Local onde ocorreu & Tempo que ocorreu \\
\hline Entorse & 13 & $\begin{array}{l}\text { Tornozelo (11) } \\
\text { Joelho (1) }\end{array}$ & $\begin{array}{l}\text { Futsal (4) } \\
\text { Artes Marciais (1) } \\
\text { Dança (1) } \\
\text { Atletismo (1) } \\
\text { Paddle (2) } \\
\text { Futebol } 11 \text { (1) } \\
\text { Volei (1) } \\
\text { Handebol (2) } \\
\text { Educação Física (1) }\end{array}$ & $\begin{array}{l}3 \text { meses atrás }(1) \\
6 \text { meses atrás }(1) \\
1 \text { ano atrás }(3) \\
2 \text { anos atrás }(4) \\
3 \text { anos ou mais }(4)\end{array}$ \\
\hline Fratura & 4 & $\begin{array}{l}\text { Pé (1) } \\
\text { Dedo da mão (1) } \\
\text { Perna (1) } \\
\text { Tornozelo (1) }\end{array}$ & $\begin{array}{l}\text { Artes Marciais (2) } \\
\text { Futebol } 11(1) \\
\text { Saltando Muro (1) }\end{array}$ & $\begin{array}{l}6 \text { meses atrás }(1) \\
2 \text { anos atrás }(1) \\
3 \text { anos atrás }(2)\end{array}$ \\
\hline
\end{tabular}




\begin{tabular}{|c|c|c|c|c|}
\hline Distensão Muscular & 7 & $\begin{array}{l}\text { Coxa Anterior (4) } \\
\text { Coxa Posterior (2) } \\
\text { Lombar (1) }\end{array}$ & $\begin{array}{l}\text { Futsal (5) } \\
\text { Handebol (1) } \\
\text { Educação Física (1) }\end{array}$ & $\begin{array}{l}3 \text { meses atrás }(1) \\
6 \text { meses atrás }(1) \\
1 \text { ano atrás }(2) \\
2 \text { anos atrás }(2) \\
3 \text { anos ou mais }(1)\end{array}$ \\
\hline Contratura muscular & 2 & $\begin{array}{l}\text { Coxa Anterior (1) } \\
\text { ombro (1) }\end{array}$ & $\begin{array}{l}\text { Atletismo (1) } \\
\text { Handebol (1) }\end{array}$ & 2 anos atrás $(2)$ \\
\hline Luxação & 3 & $\begin{array}{l}\text { Joelho (1) } \\
\text { Ombro (2) }\end{array}$ & $\begin{array}{l}\text { Dança (1) } \\
\text { Educação Física (1) } \\
\text { Parkour (1) }\end{array}$ & $\begin{array}{l}1 \text { ano atrás (1) } \\
3 \text { anos ou mais (2) }\end{array}$ \\
\hline Traumatismo & 1 & Mão (1) & Volei de areia (1) & 1 ano atrás (1) \\
\hline $\begin{array}{l}\text { Deslocamento da } \mathrm{Pa}- \\
\text { tela ocasionando semi- } \\
\text {-ruptura do ligamento } \\
\text { lateral }\end{array}$ & 1 & Joelho & Tênis & 3 anos ou mais \\
\hline Não relatou lesão & 7 & ----------- & \begin{tabular}{|l}
------------- \\
\end{tabular} & |--------------- \\
\hline
\end{tabular}

Esses resultados vão ao encontro dos resultados obtidos por Carazzato et al. (1998), que constatou que os tipos mais comuns de lesões em atletas jovens são o entorse de tornozelo, lombalgia e entorse de joelho. De mesmo modo, Powell e Barber-Foss (2000) observaram maior ocorrência das lesões, entorses e lesões musculares. Taylor e Attia (2000) relatam que as lesões mais comuns são os entorses e luxações (32\%), fraturas $(29,4 \%)$ e contusões $(19,3 \%)$.

Em muitos casos, as pessoas não se recuperam adequadamente após um período de tratamento ou não interrompem os exercícios após os primeiros sinais de dor. O desgaste crônico é a causa de muitas lesões, que são resultados de movimentos repentinos que afetam tecidos susceptíveis.

Conforme o estudo de Conte et al. (2001) a distribuição das lesões desportivas segundo variáveis descritivas de interesse, revelando como mais frequente no plano tegumentar a contusão, no muscular o estiramento e no osteoarticular o entorse.Quanto às regiões mais afetadas, destacam-se o joelho, dedos e abdome e, finalmente, a modalidade coletiva de maior incidência foi o futebol e, entre as modalidades individuais, o atletismo.

Observa-se, pela análise dos dados da tabela 1, que muitos alunos não fazem somente a prática das disciplinas do curso de Educação Física, mas desempenham, também, atividades esportivas extracurriculares em equipes ou por lazer.

A incidência de dores nos alunos participantes deste estudo foi bastante elevada, pois apenas 3 indivíduos não relataram qualquer dor, já os outros 17 alunos da amostra relataram sentirem dor em pelo menos um local. Os locais anatômicos onde apresentaram maior ocorrência de dor foram: joelho esquerdo e coluna lombar com 10 relatos, joelho direito, ombro direito/ tórax superior e pescoço com 8 relatos (tabela 2).

A intensidade dessas dores ocorre conforme a vivência dos alunos; como relata Caudill (1998), a dor indica um dano ao corpo e é um processo complexo e sua percepção consciente pode ser ampliada e reinterpretada pelas experiências das pessoas.
Tabela 2: Análise da dor

\begin{tabular}{|c|c|c|}
\hline Local Anatômico & Intensidade & Freq. \\
\hline Face & Perceptível & 2 \\
\hline Pescoço & $\begin{array}{l}\text { Perceptível } \\
\text { Moderada }\end{array}$ & $\begin{array}{l}7 \\
1 \\
\end{array}$ \\
\hline Abdômen & $\begin{array}{l}\text { Perceptível } \\
\text { Moderada }\end{array}$ & $\begin{array}{l}2 \\
1 \\
\end{array}$ \\
\hline Ombro Esquerdo / Tórax Superior & $\begin{array}{l}\text { Perceptível } \\
\text { Moderada }\end{array}$ & $\begin{array}{l}2 \\
2 \\
\end{array}$ \\
\hline Ombro Direito/ Tórax Superior & $\begin{array}{l}\text { Perceptível } \\
\text { Moderada }\end{array}$ & $\begin{array}{l}5 \\
3 \\
\end{array}$ \\
\hline Cotovelo Direito & $\begin{array}{l}\text { Perceptível } \\
\text { Moderada }\end{array}$ & $\begin{array}{l}3 \\
1\end{array}$ \\
\hline Cotovelo Esquerdo & Perceptível & 1 \\
\hline Antebraço Direito & $\begin{array}{l}\text { Perceptível } \\
\text { Moderada }\end{array}$ & $\begin{array}{l}3 \\
1 \\
\end{array}$ \\
\hline Antebraço Esquerdo & Perceptível & 1 \\
\hline Mão/ Punho Direito & Perceptível & 2 \\
\hline Mão/ Punho Esquerdo & Perceptível & 2 \\
\hline Coluna Lombar & $\begin{array}{l}\text { Perceptível } \\
\text { Moderada }\end{array}$ & $\begin{array}{l}6 \\
4\end{array}$ \\
\hline Região Pélvica & $\begin{array}{l}\text { Perceptível } \\
\text { Moderada }\end{array}$ & $\begin{array}{l}1 \\
1 \\
\end{array}$ \\
\hline Nádegas & Perceptível & 2 \\
\hline Quadril/ Coxa Direita & $\begin{array}{l}\text { Perceptível } \\
\text { Moderada }\end{array}$ & $\begin{array}{l}4 \\
1 \\
\end{array}$ \\
\hline Quadril/ Coxa Esquerda & Perceptível & 4 \\
\hline Joelho/ Direito & $\begin{array}{l}\text { Perceptível } \\
\text { Moderada }\end{array}$ & $\begin{array}{l}3 \\
5\end{array}$ \\
\hline Joelho Esquerdo & $\begin{array}{l}\text { Perceptível } \\
\text { Moderada }\end{array}$ & $\begin{array}{l}7 \\
3 \\
\end{array}$ \\
\hline Perna Direita & $\begin{array}{l}\text { Perceptível } \\
\text { Moderada }\end{array}$ & $\begin{array}{l}1 \\
2\end{array}$ \\
\hline Perna Esquerda & Moderada & 2 \\
\hline Tornozelo Direito & Moderada & 4 \\
\hline
\end{tabular}




\begin{tabular}{l|l|l}
\hline Tornozelo Esquerdo & $\begin{array}{l}\text { Perceptível } \\
\text { Moderada }\end{array}$ & 2 \\
\hline Pé Direito & Perceptível & 2 \\
\hline Pé Esquerdo & Perceptível & 3 \\
\hline Fonte: Dados da pesquisa
\end{tabular}

Os resultados da Imagem Corporal apontam que os alunos do curso de Educação Física estão satisfeitos com seu corpo. A Tabela 3 nos mostra que a diferença entre a média da Imagem Corporal Real e a Imagem Corporal Ideal é de apenas 0,25. Segundo Troyse (1997), a imagem corporal é uma fotografia que temos sobre a aparência do nosso corpo unida a atributos e sentimentos a respeito dessa imagem.

Alguns autores culpam a mídia por divulgar uma imagem irreal do ideal de beleza para as mulheres. Fato inegável é que vem aumentando a cada dia o número de mulheres descontentes com o próprio corpo e a incidência dos distúrbios alimentares (PICKERING, 1996). O descontentamento com o próprio corpo tem levado especialmente as mulheres, à prática de dietas restritivas.

Tabela 3: Escala de silhueta (Stunkard)

\begin{tabular}{l|c|c|c|c}
\hline VARIÁVEL & X & DP & min. & máx. \\
\hline Imagem Corporal Real & 3,4 & 1,14 & 1 & 6 \\
\hline Imagem Corporal Ideal & 3,65 & 1,04 & 2 & 5 \\
\hline
\end{tabular}

Fonte: dados da pesquisa

O’Dea; Abrahan. (2001) estudaram diferenças no conhecimento e comportamentos para perda de peso, desordens alimentares e imagem corporal entre estagiários de economia e professores de educação física, com idade média de 22 anos, e verificaram que os dois grupos têm um inadequado nível de conhecimento e comportamento relacionado à nutrição, perda de peso e imagem corporal.

Entre as mulheres, identificou-se que $47 \%$ fizeram algum tipo de dieta para perda de peso, a despeito de apresentar um corpo dentro dos padrões considerados normais ou mesmo ser magra, além de adotarem práticas como uso de laxantes, provocarem vômitos, utilizarem produtos dietéticos, entre outros.

Pesquisas com outros grupos universitários não diferiram muito dos resultados achados no presente estudo. Entre estudantes de nutrição na cidade do Rio de Janeiro, Bosi et al. (2006), encontraram média de 81,2 $\pm 33,6$ para o BSQ. Nesta investigação, os autores identificaram uma quantidade menor $(40,4 \%)$ com tendências apreensivas em relação às formas corporais. Em outra pesquisa abrangendo universitárias utilizando o BSQ, Stipp; Oliveira (2003) detectaram que $44,2 \%$ das alunas de nutrição e 48,9\% de psicologia manifestaram distorções ligadas à imagem corporal.

Tabela 4: Body Shape Questionnaire (BSQ)

\begin{tabular}{l|c}
\multicolumn{1}{c|}{ CLASSIFICAÇÃO } & FREQUÊNCIA \\
\hline Nenhuma Alteração & 15 \\
\hline Leve & 3 \\
\hline Moderada & 1 \\
\hline Grave & 1
\end{tabular}

Body Shape Questionnaire - BSQ (COOPER et al., 1987)
Palma et al. (2005) puderam verificar que as pressões em relação ao corpo dos profissionais desta área que atuam em academias de ginástica têm sido elevadas. Fato igualmente destacado por Mookeriee; Singh (2002). Neste sentido, as alunas ao tentarem realizar estágios em academias poderiam, de forma semelhante, sofrerem constrangimentos ligados ao tipo físico do corpo.

Com a utilização de dois instrumentos para verificar a satisfação com a Imagem Corporal, notou-se uma pequena diferença nos resultados das Tabelas 3 e 4. Na Tabela 3 os resultados nos sugerem que os alunos do Curso de Educação Física estão satisfeitos com sua imagem corporal, mas observando a Tabela 4 podemos observar que 5 alunos apresentam alguma alteração quanto a satisfação da imagem corporal.

Em relação à imagem corporal, nota-se uma carência de estudos que abranjam ambos os sexos, pois na maioria das pesquisas encontradas na literatura foram realizadas somente com mulheres. Ainda que as mulheres se preocupem mais com essa questão, na sociedade moderna os homens têm a preocupação em relação com a aparência física aumentada significativamente.

\section{Conclusão}

Com os dados obtidos pode-se observar que, apesar dos alunos terem relatado sentirem inúmeras dores, terem sofrido diversas lesões, isso parece não ter afetado a capacidade para o trabalho. Este estudo pode trazer indícios de uma realidade; porém a partir desta pesquisa torna-se precipitado certificar esses resultados, pois o tema tem caráter subjetivo e complexo. Esta pesquisa serve de referencial inicial para possíveis pesquisas mais abrangentes e com amostragens maiores, pois sinaliza para a confirmação de alguns resultados que carecem de maiores confirmações.

Analisando os resultados do índice de capacidade para o trabalho e fazendo uma relação com os dados dos questionários de imagem corporal, verifica-se um indício de que existe a relação entre estar satisfeito com a sua imagem corporal e a sua capacidade de desempenhar suas tarefas.

Sugere-se que se estenda esta pesquisa para além da Universidade Federal de Santa Maria, enriquecendo-a com outras instituições públicas e privadas de modo a chegar-se a um resultado que permita a generalização a fim de promover propostas de efetiva conscientização do problema, como forma de preservação da saúde e integridade física dos futuros profissionais de Educação Física.

\section{Referências}

ANDRADE, C. B.; MONTEIRO M. I. Envelhecimento e capacidade para o trabalho dos trabalhadores de higiene e limpeza hospitalar. Revista da Escola de Enfermagem, v. 41, n. 2, p. 237-244, 2007.

BELLUSCI, S. M.; FISCHER, F. Envelhecimento e condições de trabalho em servidores forenses. Revista Saúde Pública, São Paulo, v. 33, n. 6, 1999.

BLOWERS, L. C. et al. The relationship between sociocultural pressure to be thin and body dissatisfaction in preadolescent girls. EatingBehaviors, v. 4, p. 229-244, 
2003.

BOSI, M. L. M. et al. Autopercepção da imagem corporal entre estudantes de nutrição: um estudo no município do Rio de Janeiro. Jornal brasileiro de psiquiatria, v. 55, p. 108-113, 2006.

CARAZZATO, J. G. et al. Incidência de lesões pregressas do aparelho locomotor encontradas em avaliação global de 271 atletas jovens de elite de dez modalidades esportivas.

Revista Brasileira Ortopedia, 1998.

CASH, T.; PRUZINSKY, T. Body images. New York: Guilford Press, 1990.

CAUDILL, M. Controle a dor ante que ela assuma o controle: um programa clinicamente comprovado. São Paulo: Summus, 1998.

CONTE, M. et al. Exploração de fatores de risco de lesões desportivas entre universitários de educação física: estudo a partir de estudantes de Sorocaba/SP. Revista Brasileirade Medicina do Esporte, v. 8, n. 4, 2002.

CONTI, M. A.; FRUTUOSO, M. F. P.; GAMBARDELLA, A. M. D. Excesso de peso e insatisfação corporal em adolescentes. Revista de Nutrição, Campinas, v.18, n. 4, p. 491-7, 2005.

COOPER, P. J. et al. The development and validation of the Body Shape Questionnaire.Int J Eating Dis, v. 6, n. 4, p. 485, 1987.

COUTO, H. A. Como gerenciar a questão das LER/ DORT. Belo Horizonte: Ergo; 1998.

DAMASCENO, V. O. et al. Imagem corporal e corpo ideal. Revista Brasileira de Ciência e Movimento, v. 14, p. 8194, 2006.

DORE, B. F.; GUERRA, R. O. Prevalência e fatores associados à dor em bailarinos profissionais. 2006. 49 f. Dissertação (Mestrado em Ciências da Saúde) Universidade Federal do Rio Grande do Norte, Natal, 2006.

DUARTE, M. A.; GOULART, E. M. A.; PENNA, F. J. Limiar de dor e idade na infância e adolescência. Jornal de Pediatria, v. 75, n. 4, p. 244-248, 1999.

FISCHER, F. M. et al. A (in)capacidade para o trabalho em trabalhadores de Enfermagem. Revista Brasileira de Medicina do Trabalho, v. 3, n. 2, p. 97-103, 2005.

FLEGEL, M. J. Primeiros socorros no esporte: o mais prático guia de primeiros socorros para o esporte. São Paulo: Manole, 2002.

GANTUS, M. C.; ASSUMPÇÃO, J. D. Epidemiologia das lesões do sistema locomotor em atletas de basquetebol.

ActaFisiátrica,v. 9, n. 2, p. 77-84, 2002.

KENDALL, F. P.; McCREARY, E. K. Músculos: provas e funções. São Paulo: Manole, 1987.

KOLT, G. S.; SNYDER-MACKLER, L. Fisioterapia no esporte e no exercício. Rio de Janeiro: Revinter: 2008.

LEONHARD, M. L.; BARRY, N. J. Body image and obesity: effects of gender and weight on perceptual measure of body image. AddictBehaviors, v. 23, n.1, p. 31-34, 1998.

MACIEL, R. H. Prevenção da LER/DORT: o que a ergonomia pode oferecer. Caderno de Saúde do trabalhador. Instituto Nacional de Saúde no Trabalho: Kingraf, 2000.

MADRIGAL, H. et al. Underestimation of body mass index through perceived body image as compared to self-reported body mass index in the European Union. Public Health, v. 114, n. 6, p. 468-73, 2000.

MARTINEZ, M. C.; LATORRE, M. R. D. O. Saúde e capacidade para o trabalho em trabalhadores de área administrativa. Revista Saúde Pública, v. 40, n. 5, p. 851868, 2006.

MIGUEL, A. Dor crônica: instrumentos de avaliação. 2007. Disponível em: <www.medicinageriatrica.com. br/2007/05/13/saude-geriatria/dor-cronica-instrumentos-deavaliacao>. Acesso em: 21 set. 2008.

MOFFAT, M.; VICKERY, S. Manual de manutenção e reeducação postural da American PhysicalTherapyAssociation. Porto Alegre: Artmed, 2002.

MONTEIRO, M. S.; ALEXANDRE, N. M. C.; RODRIGUES, C. M. Doenças músculo esqueléticas, trabalho e estílo de vida entre trabalhadores de uma instituição pública de saúde. Revista da Escola de Enfermagem, v. 40, n. 1, p. 20-25, 2006.

MONTEIRO, M. I.; FERNANDES, A. C. P. Capacidade para o trabalho de trabalhadores de empresa de tecnologia da informação. Revista Brasileira de Enfermagem, v. 59, n. 5, p. 603-608, 2006.

MOOKERIEE, S.; SINGH, J. Anthropometric profiles and social physique anxiety of physical education professionals from India. PerceptMotSkills, v. 94, p. 47-54. 2002.

MORGADO, F. F. R. et al. Análise dos instrumentos de avaliação da imagem corporal. Fitness \&Performance Journal, v. 8, n. 3, p. 204-211, 2009.

MUROFUSE, N. T.; MARZIALE, M. H. P. Mudanças no trabalho e na vida de bancários portadores de lesões por esforços repetitivos: LER. Revista Latino Americana de Enfermagem, v. 9, n. 4, p. 19-25, 2001.

O'DEA J. A.; ABRAHAM S. Knowledge, beliefs, attitudes, and behaviors related to weight control, eating disorders, and body image in Australian Trainee Home Economics and Physical Education Teachers. Journal of Nutrition Education, v. 33, p. 332-340, 2001. 
O’DEA, J. A. G. Ethnicity, culture and social class influences on childhood obesity among Australian schoolchildren: implications for treatment, prevention and community education.Health \&Social Care Community, v. 16, n. 3 , p. $282-290,2008$.

OLIVEIRA, C. R. Lesões por esforços repetitivos (LER). Revista Brasileira de Saúde Ocupacional, v. 73, p. 59-85, 1991.

PALMA, A.; ASSIS, M. Uso de esteróides anabólicoandrogênicos e aceleradores metabólicos entre professores de educação física que atuam em academias de ginástica.

Revista Brasileira de Ciências do Esporte, v. 27, p. 75-92, 2005.

PASTRE, C. M. et al. Lesões desportivas no atletismo: comparação entre informações obtidas em prontuários e inquéritos de morbidade referida. Revista Brasileira de Medicina do Esporte, v. 10, n. 1, 2004.

PAXTON, S. J.; EISENBERG, M. E.; NEUMARCKSZTAINER, D. Prospective predictors of body dissatisfaction in adolescent girls and boys: a five-year longitudinal study. Developmental Psychology, v. 42, p. 888-99, 2006

PESA, J. A.; SYRE, T. R.; JONES, E. Psychosocial differences associated with body weight among female adolescents: the importance of body image. Journal of Adolescent Health, v. 26, n. 5, p. 330-337, 2000.

PICKERING, A. S.; TIGGEMANN, M. Role of television in adolescent women's body dissatisfaction and drive for thinness. The International Journal of Eating Disorders, v. 20 , n. 2 , p. $199-203,1996$

POPE, J. R. H. G.; PHILLIPS, K. A.; OLIVARDIA, R. O complexo de adônis obsessão masculina pelo corpo. Rio de Janeiro: Campus, 2003.

POWELL, J. W.; BARBER-FOSS, K. D. Sex-related injury patterns among selected high school sports. The American Journal of Sports Medicine, v. 28, n. 3, p. 385-391, 2000.

REGIS FILHO, G. I.; MICHELS, G.; SELL, I. Lesões por esforços repetitivos/distúrbios osteomusculares relacionados ao trabalho em cirurgiões-dentistas. Revista Brasileira de Epidemiolgia, v. 9, n. 3, p. 346-359, 2006.

RICCIARDELLI, L. A.; McCAB, M. P.; BANFIELD, S. Sociocultural influences on body image and body changes methods. Journal of adolescent health, v. 26, n. 1, p. 3-4, 2000

RIGOTTI, M. A.; FERREIRA, A. M. Intervenções de enfermagem ao paciente com dor. Revista Ciência e Saúde, v. 12 , n. 1, p. $50-54,2005$.

ROBINSON, T. N. et al. Overweight concerns and body dissatisfaction among third-grade children: the impacts of ethnicity and socioeconomic status. Journal Pediatric. v.
138, p. 181-187, 2001.

SALIM, C. A. Doenças do trabalho: exclusão, segregação e relações de gênero. São Paulo em Perspectiva, v. 17, n. 1, p. 11-24, 2003.

SANTOS, A. C. O exercício físico e o controle da dor na coluna. Rio de Janeiro: MEDSI, 1996.

SCHILDER, P. A imagem do corpo: as energias construtivas da psique. 3. ed. São Paulo: Martins Fontes. 1999.

STIPP, L. M.; OLIVEIRA, M. R. M. Imagem corporal e atitudes alimentares: diferenças entre estudantes de nutrição e de psicologia. Saúde em Revista, v. 5, n. 9, p. 47-51, 2003.

STUNKARD, A. J.; SORENSEN, T.; SCHLUSINGER, F. Use of the Danish adoption register for the study of obesity and thinness. In: KETY S. S. et al. Genetics of neurologic and psychiatric disorders. New York: Raven Press, 1983.

SULJOLDZIC, A.; DE LUCIA, A. A cross-cultural study of adolescents-BMI, body image and psychological wellbeing. Coll Antropol. v. 31, p. 123-130, 2007.

TAYLOR, B. L.; ATTIA, M. W. Sports-related injuries in children. Academic Emergency Medicine, v. 7, n. 12, p. 1376-1382, 2000.

THOMPSON, J. K. Body image, eating disorders and obesity. Washington D. C.: American Psychological Association, 1996.

TROYSE, E. R. Impacto de la figura corporal em el desarrollopsicosocialdel niño y el adolescente. Pediatría, v. 64, n. 3, p. 128-131, 1997.

TUOMI, K. et al. Índice de capacidade para o trabalho. São Carlos: UFSCar, 2005.

TUOMI, K. et al. Organizational practices, work demands and the well-being of employees: a follow-up study in the metal industry and retail trade. Occupational Medicine, v. 54, p. 115-121, 2004.

TUOMI, K. et al. Work ability index. Helsinki: Finnish Institute of Occupational Health, 1998.

VAHL NETO, E. Qualidade de vida e capacidade de trabalho em diferentesfaixas etárias dos funcionários da CELESC. 1999. 107 fls. Dissertação (Mestrado em Engenharia de Produção) - Programa de Pós-Graduação em Engenharia de Produção, UFSC, Florianópolis, 1999.

WALSH, I. A. P. et al. Capacidade para o trabalho em indivíduos com lesões músculoesqueléticas crônicas. Revista Saúde Pública, v. 38, n. 2, p. 149-156, 2004. 